team should use the Care Programme Approach, deciding on the appropriate key worker for each referred patient. Follow-up of discharged patients from specialist care should be carefully planned and might involve consultant, general practitioner and community psychiatric nurse seeing the patient by arrangement on different occasions. Specialist mental health services both in hospital and in the community, should concentrate on the severely mentally ill, and services should only be extended to others when the needs of this group have been met. Purchasers, in order to achieve the targets of the Health of the Nation for the severely mentally ill, will need to maximise the effectiveness of mental health professionals; this implies concentrating the work of CPNs within the specialist multidisciplinary team upon caring for the severely mentally ill.

\section{References}

Departiment of Health (1990) Care Programme Approach Circular HC(90)23/LASSL(90)11. London: Department of Health.

National Health Service Management Executive (1992) Guidance on the extension of the Hospital and Community Health Services elements of the GP fundholding scheme from 1 April 1993 EL(92)48. London: Health Care Directorate.

Royal College of Psychintrusts (1991) The future of psychotherapy services. Psychiatric Bulletin, 15, 174-179. - (1992) Mental Health of the Nation: The Contribution of Psychiatrists. London: Royal College of Psychiatrists.

Secretary OF State for Health (1992) The Health of the Nation: A Strategy for Health in England 1986. London: HMSO

WhITE, E. (1991) The Third Quinquennial National Community Psychiatric Nursing Survey. Leeds CPMA Publications.

\title{
Read codes for the mental health professions: the Clinical Terms Project
}

\author{
JoHN WING, Director, College Research Unit
}

\section{An essential first step}

In mid-1991, the Conference of Medical Royal Colleges and their Faculties initiated an Advisory Group on Information Services with broad representation from the profession, the NHS Management Executive, and the Department of Health. The aim of the group is to facilitate and co-ordinate input from the profession to the NHS Information and Technology Strategy. It is chaired by Sir Duncan Nichol, NHS Chief Executive.

It was agreed that an essential first step towards building a more clinically useful Health Information System would be to establish an agreed nomenclature, or thesaurus, of terms at present used in NHS clinical records, each one with a unique identifier (the Read Code). Proposals for what has become the Clinical Terms Project, made by Dr Martin Severs, Chairman of the Conference Information Group, and Dr James Read, Director of the NHS Centre for Coding and Classification (CCC), were approved in March 1992.

The aims of the project are very simple, to provide: terms representing preferred clinical concepts agreed synonyms and eponyms for these terms agreed abbreviations

an agreed structure for convenient search and display.

It does not aim to provide:

a glossary or dictionary of differential definitions

a minimum clinical data set

a set of outcome measures

a functioning clinical information system.

The project will, however, build a platform from which such further projects can be taken forward with confidence that compatibility can be achieved throughout the NHS. This first stage will be completed by 1 October 1993.

\section{Method of working}

The majority of the work is being done by 40 Specialty Working Groups (SWGs) covering the NHS, each of which develops the section of terminology for which it is responsible while maintaining close liaison with overlapping fields. There is an elaborate quality control procedure. Representatives of all $\mathbf{4 0}$ meet at regular intervals at the CCC headquarters in Loughborough, where there is an 
atmosphere of critical but enthusiastic participation in solving the problems presented by individual SWGs.

The members of the mental health SWG are John Wing (Chair and member of the Conference Information Group), Mark Berelowitz, Marc Binns (British Psychological Society), Alistair Burns, John Cox, Paul Lelliott, Shôn Lewis, Robert Macrowan (Nursing), Chris Payne (CCC), Susannah Root (Research Worker), Ben Sacks, Pamela Taylor, Digby Tantam, Eric Taylor and Simon Wessely. Members representing substance use and social work are about to be appointed. Each member works with a group of consultants in order to make use of a wide range of expertise and establish a broad spread of ownership for the thesaurus. There are special mechanisms for dealing with the substantial overlap with other groups such as Geriatrics, Neuroscience and Paediatrics.

We started by providing codes for ICD-10 disorders, and a mapping structure for ICD-9 and DSM-III-R. This was not a simple task because of the very substantial changes in ICD-10 but the task was finished on time in mid-February. DSM-IV will follow in due course.

Codes for investigations, procedures and therapies form the second priority, to be completed by mid-May. Fortunately nearly all medications and side-effects already have Read codes.

The largest and trickiest part of the work is providing codes and structure for most (say, 80\%) complaints, symptoms and behaviours, to be delivered by early August, leaving time for further piloting before the final deadline. A structure is necessary for an orderly approach to the task, and for display, search and browsing functions. However, it is important to understand that the codes will support any classification.

\section{The context: Mental Health Information Systems (MHIS)}

Thus an important function of Read Codes for all the health professions is to underpin the construction and compatibility of computerised clinical information systems. The preparatory work is proceeding according to timetable. The wider clinical objective is being co-ordinated, across the whole range of the health services including in-patient, community and primary care, by the Conference Information Group.

The Council of our College has just approved the establishment of a Special Committee to be chaired by the Registrar, to take forward the work of the MHIS Working Party of the Research
Committee (Chairman, Professor Roy McClelland). The Working Party's report (1992) has set out a strategy by which a 'bottom-up' system can be created and the functions that should be supported by such systems:

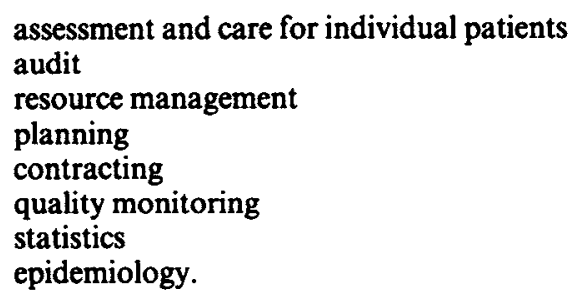

A minimum clinical data set has been drafted for wide discussion and piloting by mental health professionals.

The College Research Unit, the MHIS Working Party and the Institute of Health Service Management jointly sponsored a conference on information in psychiatry on 21 January. It was sold out. The Unit has published a preliminary survey of MHIS that meet minimum criteria and are already working in Health Districts (Lelliott $e t$ al, 1993), a document on coding (Shanks, 1992), and a document on epidemiologically based needs assessment (Wing, 1992). The Unit is also conducting a project to create a set of brief scales for measuring outcomes that can help to assess progress towards the mental health targets set in Health of the Nation (1992), and fill the gap before MHIS are widely adopted. Finally, the Unit convenes a liaison group that brings together many of the agencies working in the field. At the last meeting, plans were agreed to undertake joint projects to test techniques and work towards establishing comparability.

The clinical terms project, therefore, is part of a general process of development, in which the College is already carrying out a pioneering role.

\section{References}

Department of Health (1992) The Health of the Nation. A Strategy for Health in England. London: HMSO.

Lellott, P., Flannigan, C. \& Shanks, S. (1993) A Functional Review of Seven MHIS. Available from College Research Unit.

Report of the Mental Health Information Systems Working Party (1992) Available from College Research Unit.

Shanks, S. (1992) Coding and Mental Health Information. A review of current approaches. Available from College Research Unit.

Wing, J. K. (1992) Epidemiologically Based Needs Assessment. Report 6. Mental Illness. To be published by HMSO, 1993. Available from College Research Unit. 